Mr. Wakefield washed out the stomach at first twice and then once daily, then from two to three times per week for 16 weeks. During this time all symptoms and signs had gradually disappeared and the patient is now, at the age of two years and seven months, a bonny, healthy child weighing 35 pounds.

At the present time I have under my care in King's College Hospital an infant who, at the age of three weeks, was brought with the usual history and the two characteristic signs. My house physician, Mr. G. P. Young, has washed the stomach out twice daily for ten weeks and although for the first five weeks the weight was almost stationary and some vomiting continued the weight then began to rise and the child, whose weight on admission was 5 pounds 14 ounces and who was so feeble and puny that laparotomy would have been a desperate measure, has gained 22 ounces in the last five weeks and now weighs 7 pounds 4 ounces and has altogether more strength and vitality.

In another case an emaciated infant, with the usual signs and symptoms of pyloric hypertrophy, aged seven weeks, and already "almost too feeble to cry," was treated by stomach washing for six weeks; at first she gained weight slowly if at all and after about a month was only half an ounce heavier than when washing began; then she began to gain weight steadily and in 13 days had gained $13 \frac{1}{2}$ ounces. The child being now stronger it was decided to operate. From the day of the operation, although the vomiting was stopped thereby, continuous marasmus occurred and the child died in convulsions 25 days after the operation. It is easy to be wise after the event but here the steady gain in weight which had commenced before the operation makes it probable, in the light of the two cases already mentioned, that had the stomach washing alone been continued the child would have recovered.

In one case after washing out the stomach for 14 weeks there had been a gain of 22 ounces but progress was so slow that operation was done and the child recovered. In two other cases where stomach washing was done for a few days only there had already been slight gain in weight but it was decided to operate.

Whether the weight rises at once or not there is usually a marked diminution of the vomiting after the stomach has been washed out for a few days; but this must not be taken as an indication for stopping the stomach washing until the infant has been making steady and considerable progress in weight for several weeks.

Having said thus much of the success of stomach washing in this condition it is only right to mention its failures and possible risks; in four cases where stomach washing was tried for a few days only there was no improvement; in one case death occurred with some pyrexia about 48 hours after stomach washing was begun, and although the necropsy showed no evidence of vomited material in the respiratory passages death may have been due to matter drawn into the lungs in vomiting during the stomach washing; if so it must be an exceedingly rare accident, for I have had infants' stomachs washed out many hundreds of times without such an occurrence. In another case a dry rotten tube was inadvertently used and the end broke off in the stomach, necessitating immediate resort to the operative treatment which we had intended to defer; the pylorus was stretched, but an accidental rupture of its wall was overlooked (the operation was done in great haste owing to extreme feebleness of the infant), and death occurred about 27 hours later. Such exceedingly rare accidents must, however, weigh but little, and I think it remains true that stomach washing is a procedure which should certainly be tried in the pyloric hypertrophy of infants before resorting to operation; in some cases it is sufficient alone to secure complete recovery, in others by increasing the nutrition and the strength of the infant and by enabling us to postpone operation till the infant is a few weeks older it increases the chances of success from operation; where, however, the weight is steadily diminishing for several days in spite of stomach washing the question of immediate operation must be considered.

Lastly, I would insist upon an important point-namely, that the degree of gastric peristalsis (I mean the size of the bulging wave which is seen) and the palpability of the hard pylorus are no criterion of the possibility or even probability of recovery or improvement by stomach washing or of the likelihood of necessity for operation; the most pronounced signs and symptoms may occur in cases which respond well to stomach washing alone.

Operative treatment. - The actual operation to be done, if any be necessary, is a question which falls outside my province ; forcible dilatation of the pylorus, pyloroplasty, and gastro-enterostomy have each their advocates. Nine cases out of the 20 included in my series (one of which was only seen by me once in consultation and was subsequently operated upon successfully by Mr. H. J. Stiles of Edinburgh) were treated by forcible dilatation of the pylorus-all except one by my colleague, Mr. F. Burghardand seven of these nine recovered. One of these died several months later from broncho-pneumonia. Operation has risks apart from those connected with shock and with the operation itself. There is a tendency to looseness of the bowels after it and also a difficulty of nutrition which in some of my cases seemed to make death from marasmus almost inevitable for some weeks after the operation, although they ultimately recovered; an important point this, which increases the need for careful consideration before embarking on operative measures, and which increases also the importance of previous stomach washing if thereby even a few ounces of weight can be gained.

As to the proportion of cases in which operation is necessary much more experience is required before a trustworthy estimate can be formed. It must be pointed out that three of the 20 cases in my series occurred several years ago before the modes of treatment were known and two are at present under treatment. In many cases, including several in my own series, stomach washing was not tried or was given up because it was assumed that the condition was incurable without operation. That in some of the cases operation is the only method of saving life is, I think, certain, but as I have already said there is no way of determining this until other measures have been thoroughly tried.

Harley-street, W.

\section{ACUTE ASCENDING PARALYSIS IN CASES OF CHRONIC CYSTITIS.}

BY T. J. WALKER, M.D. LOND., SENIOR SURGEON TO THE PETERBOROUGH INFIRMARY.

IN the comparatively limited field offered in my private practice, general and consulting, I have met with three cases of long-standing chronic cystitis which terminated fatally by acute ascending paralysis of a most malignant type. Although urinary paraplegia has been generally recognised by the profession for 70 years, since 1833 when Stanley directed attention to the malady in a communication to the Royal Medical and Chirurgical Society, I can find no allusion by authors dealing either with urinary diseases or with Landry's paralysis to the occasional association of the latter ailment with chronic cystitis. Stanley gives a short note of the case of a man admitted with gonorrhcea and phimosis into St. Bartholomew's Hospital, under the care of Dr. Erle, who died suddenly three weeks after admission and 12 hours after paraplegia had set in ; but Stanley expressly mentions that the paralysis was not higher than the waist and as the man suddenly fell back in his bed and died the case was certainly not identical with those which occurred in my practice. Saundby gives the case of a man, aged 60 years, who was admitted into the General Hospital at Birmingham and who died four weeks after the onse of symptoms of a progressive paralysis. The disease here was possibly pathologically of the same nature although not showing the same terrible rapidity in its course as did the cases of which I will now detail the salient points.

5. CASE 1.-The patient was a man, aged 40 years. When 15 years old he fell astride a rail and injured his perineum. Ten years later he came under my care for retention of urine and stricture of the urethra and was treated in the Peter borough Infirmary. The retention had come on gradually the patient having gone about habitually with a distended bladder. He never completely lost the chronic cystitis, which did not inconvenience him greatly and did not preven his taking and working a baker's business. He seldom sought medical aid unless there was an acute exacerbation or some indication of the stricture requiring dilatation. In April, 1877, such an exacerbation occurred and the patient 
had been under treatment by my partner Dr. G. Kirkwood and myself for nearly a month when, on the morning of May $19 \mathrm{th}, \mathrm{I}$ was sent for and found that in the course of the previous night he had felt numbness in the feet and some loss of power in the legs. When I saw him there was paresis of the limbs up to the thighs. By the evening the paralysis had extended upwards to the arms and the thorax and the breathing was already embarrassed. The symptoms rapidly progressed and death took place 18 hours after their onset.

No post-mortem examination was made but it seemed probable that some direct causal relation between the urinary disease and the rapidly fatal almost fulminating ascending paralysis must exist. My notes of the case are very meagre but to the best of my recollection the patient did not require the use of the catheter or bougies during this last illness.

CAsE 2.-The patient, a man, aged 62 years, was first seen by me about the year 1877, when, in consultation with Dr, C. N. Elliott of Oundle, I operated upon him for a stricture of the meatus of the urethra for which he souglit medical aid only when the symptoms of distended bladder and cystitis with painful micturition made his life intolerable. A few years later, having come to live close to Peterborough, he came under my care and I learned that he had never lost his cystitis.

On Dec. 31st, 1886, I was called to him on account of an acute exacerbation of his bladder trouble, accompanied with much malaise and some fever. The symptoms were not urgent, there was no difficulty in micturition, and no catheter was passed. I saw him again on Jan. 2nd, 1887, when he was somewhat better. He was not visited on the 3 rd but on the early morning of the 4th he experienced uncomfortable sensations and some muscular feebleness in the lower limbs and at my visit about midday I found distinct indications of paraplegia. The sudden onset of the paralytic symptoms, with the history of long-standing cystitis, \&c., and the feeble general condition reminded me at once of the case which I had seen ten years previously. I gave a prognosis which led to the patient promptly settling his affairs. By the 5 th the symptoms had made considerable progress and early on the morning of the $6 \mathrm{th}, 48$ hours after the first indication of paralysis, the patient succumbed. A necropsy was not allowed.

CASE 3.-This case was seen by me in consultation with the late Mr. W. J. Pilcher of Boston, whose son, Mr. C. W. Pilcher, has furnished me with notes of the case. The patient, a man, aged 67 years, who resided at Boston, had for many years suffered from chronic cystitis and for the three months preceding his death had been under $\mathrm{Mr}$. Pilcher's care suffering from prostatic disease and cystitis requiring catheterisation. He had been confined to his bed for some time. On the morning of March 13th, 1894, when the patient got out of bed, he appeared feeble and unsteady on his feet. He was catheterised as usual by Mr. Pilcher and in the course of the day I was sent for. I saw the patient at about 8 P.M. I noticed when I wished to feel his pulse that the movements of the hand and arm were impaired and on further examining into the history recognised that I had another case of the same character as Cases 1 and 2. Already, only 12 hours after the onset of the symptoms indicating implication of the nerve centres, the paralysis had progressed upwards until the upper extremities were involved. With my experience of the former cases I gave a prognosis of urgent danger, demanding the immediate settlement of the patient's affairs. This opinion was justified by his death 18 hours after the first onset of the paralytic symptoms. No necropsy was made.

Each of these three cases of progressive ascending paralysis is distinguished by the sudden invasion of the attack, by its terribly rapid progress, and by the fact that it occurred as the fatal termination of a chronic cystitis. As to their pathology I am unfortunately able to give no certain information; they are recorded mainly for the benefit of those actively engaged in the prosecution of our art-those who, like myself, have little time or opportunity to advance our science.

I can recall only two other cases of Landry's paralysis of this virulent type in which I have been consulted, so that my experience is that out of five cases of this malady three were associated with urinary disease, and yet by none of the authors whom I have been able to consult is this association referred to. Farquhar Buzzard, in the important paper on the pathology and bacteriology of Landry's paralysis published in Brain, ${ }^{1}$ speaking of the associated morbid conditions met with sufficientily often to justify their mention, names only two-enlargement of the spleen and evidence of extensive pleurisy in the form of old and recent adhesions. But in the light of my experience I cannot believe that the absence of recorded cases must be taken as a proof of the rarity of the association of Landry's paralysis with disease of the urinary organs; it is rather that this association never having been recognised as causal in its nature cases have not been published. A very brief glance at the pathological history of the nervous affections known to be associated with disease of the bladder and at that of Landry's paralysis will, I think, help to show the probability of the occurrence of cases such as those which $I$ am reporting in which, as I believe, the one disease gave rise to the other. Although rarely allucled to by writers on diseases of the urinary organs, " urinary paraplegia" has, as I have already said, been recognised since Stanley, in 1833, directed attention to the malady, accounting for it in accordance with the dominant pathological theory of that date as a form of reflex paralysis, and even 53 years before this Troja (as quoted by Leyden ${ }^{2}$ ) stated that violent inflammation of the kidney may produce an irritation of the nerves of that organ which may extend to the nerves of the spinal cord giving rise to paralysis and loss of sensation in the lower limbs.

Gull, in a paper published in Guy's Hospital Reports for 1861 , attacked the wavering faith in the nervous reflex view of the pathology of urinary paraplegia, conlending that it was due to an inflammation of the cord which escaped de tection in fatal cases owing to the imperfection of the examinations made at that time (1861). In this paper he enumerates the characteristics of urinary paraplegia under 15 heads, the second, third, and fourth of these being: (2) usually only lower limbs paralysed; (3) no gradual ex tension of the paralysis upwards; and (4) usually paralysis incomplete; from which it is clear that every character of "the symptom complex" (Farquhar Buzzard) which we call Landry's paralysis is wanting in "urinary paraplegia" as hitherto described.

Leyden, ${ }^{3}$ in a clinical lecture on the subject of reflex paralysis, goes fully into the history and pathology of urinary paraplegia and he concludes that in a considerable number of cases of paraplegia urinaria an anatomical affection of the cord has been proved in the form of a myelitis which begins in a circumscribed lesion in the upper part of the lumbar enlargement. He assumes that the inflammation first passes to the nerves and induces in them a progressive neuritis which, as has been proved by experiment, may lead to myelitis. He conclucles that this may therefore be looked upon as the most natural and frequent mode of occurrence in paraplegia urinaria.

Hurry Fenwick, ${ }^{4}$ who gives a fuller consideration to the matter than any other of the writers on urinary diseases whom I have been able to consult, while he points out that it would be rash to throw over entirely the possibility of reflex paralytic symptoms in connexion with urinary diseases, accepts the more recent view of the pathology of urinary paraplegia as expounded by Leyden and others.

Beyond this stage the pathology of urinary paraplegia has not been advanced. I can find no record of bacteriological investigation in this malady. Affections of the bladder associated with, but secondary to, disease of the nervous system have not, I think, any bearing on the question under consideration, therefore I now pass briefly to the history of Landry's paralysis, by which I mean acute ascending paralysis such as that which proved fatal to my patients, a mortal malady which until now, as Farquhar Buzzard points out, is to us only a " symptom-complex," not a disease.

Landry, in his original paper, ${ }^{5}$ published ten cases of ascending paralysis showing a pernicious and malignant character, differing from other cases of general progressive paralysis characteristic of well-known morbid conditions in the essential point that there was in these cases an absence of every appreciable nervous lesion. This, which he regarded as the essential characteristic, can no longer be so regarded, as since 1859, when Landry's paper was published, the microscope, at first unaided by the various hardening and staining 1 Brain, 1903, p. 94.
German Clinical Lectures, New Sydenham Society, vol. lxvi.
$\mathbf{3}$ Op. cit.

4 Cardinal Srmptoms of Urinary Diseases, 1893

5 Gazette Hebdomadaire de Médecine et de Chirurgie, vol, vi., 1859. 
processes, and latterly with their most valuable help, has been brought into ase for the examination of the nervous struetures and the number of fatal cases of acute ascending paralysis in which no pathological change can be found has been proved to be very small. In the great majority there are microscopical changes in the cord and in the meninges such as could not be detected by the pathologists of 1859 , and the opinion of the most recent investigators is that the symptoms are due to an acute intoxication of the nervous system caused by microbic toxins.

Farquhar Buzzard, after a careful consideration of the results of the bacteriological and microscopical examinations of these cases, concludes that it has been shown by investigations on man and the lower animals that the clinical manifestations of Landry's paralysis are the result of a local infection, a general pyæmia, or, lastly and most frequently, of an acute intoxication. Beyond this stage he has himself advanced the pathology of the disease by his discovery of an organism which he regards as specific and as the cause of the disease, although he is careful to say that he does not as yet claim to have in any way proved that this is the only microbe that can produce the fatal toxins.

Assuming, then, that it has been proved by competent investigators that Landry's paralysis is an intoxication of the nervous centres due to infection by specific microbes and that urinary paraplegia is the result of the spreading from the urinary organs to the lumbar portion of the cord of a specific inflammation, I think we have grounds to justify a probable explanation of the pathology of the cases to which I am directing attention. In every infection three factors are necessary: (1) the presence of microbes having active infective powers; (2) a medium in which these microbes when conveyed to it can develop; and (3) the resistant power of the tissues must be weakened. I venture to suggest as a provisional view that in my cases these factors existed. First, the specific microbes were to be found in the urinary organs, probably in the bladder; secondly, at a certain stage of the disease they were conveyed along the same course, almost certainly the nerves, by which inflammation spreads from the urinary organs in paraplegia urinaria to the cord, in which medium they developed rapidly, producing a virulent intoxication; and thirdly, the tissues were weakened by the long-standing cystitis.

Whether this view be accepted or not, whether it be confirmed or disproved by future investigation, the clinical facts remain the same; and although in neither of my cases did my being able to come to a correct diagnosis and prognosis prolong or save the life of the patient, I look forward to the time when, the pathological association of this acute ascending paralysis and chronic urinary disease having been definitely established, remedial measures (probably organo-therapeutic) may be discovered which may stop the rapid course of the malady and avert its fatal termination. It is with this hope that I press these observations on the notice of my fellow practitioners and especially of those members of the profession who can devote themselves to pathological investigation.

Peterborough.

\section{FURTHER NOTES ON THE AFTER- HISTORY OF CASES OF PYLORO- PLASTY.}

BY G. GREY TURNER, M.B. DURH., F.R.O.S. ENG., SURGICAL REGISTRAR TO THE ROYAI INFIRMARY, NEWCASTLE-ON-TYNE.

IN Trre Lancet of Feb. 11th, p. 351, there appeared a short paper on Pyloroplasty by Mr. Rutherford Morison. In that paper I am credited with having followed the afterhistory of his patients and in support of this some few brief particulars of the cases are given. As a matter of fact I prepared a table giving full details of each patient with a note of their progress up to the last time I heard of them in August, 1904. This table, very much to my regret, has been lost after leaving our hands. I wish to take this opportunity of amending the very brief particulars given in Mr. Morison's paper, so that those who are interested in this subject may be better able to judge why that surgeon still adheres to an operation which appears to have a rapidly waning popularity.

CASE 1.-The patient, a woman, aged 48 years, was operated on in October, 1894. 'The pylorus was thick and firm and would not allow a pair of closed Spencer Wells forceps to pass. She has remained well ever since the operation. She takes ordinary food and has very good health. In August last she weighed 10 stones 7 pounds, which is more than double her weight at the time of the operation and about three stones more than her previous normal weight.

CASE 2.-A woman, aged 37 years, was operated upon in October, 1895. The pylorus was bound down but was oedematous and reddened and on the upper margin there was a cicatrix ; it only admitted the tip of the little finger. The patient has remained well ever since the operation. At present she has better health than she has enjoyed for years, can take any kind of food, and has no trouble whatever. In August, 1904, she weighed 9 stones-a gain of 1 stone 3 pounds since the operation.

CASE 3. - The patient, a man, aged 31 years, was operated upon in January, 1896. There was a hard nodular mass surrounding the pylorus which admitted the tip of the forefinger. The patient has been in very good health since the operation, has no stomach trouble, takes any kind of food, and in August last weighed 10 stones, a gain of 2 stones 7 pounds since the operation.

CASE 4.-A man, aged 32 years, was operated upon in August, 1896. The pylorus would only admit a pair of closed Spencer Wells artery forceps. The patient has remained well ever since; he went through the South African war without any stomach trouble and at present, in spite of drink and poor food, he has none of his old sym. ptoms. When seen in August, 1904, he had just recovered from pneumonia and looked thin and ill but he was able to take as much of any sort of food as he was able to get. His general health is better than before and he weighs 9 stones, a gain of 1 stone 9 pounds.

CASE 5.- The patient was a man, aged 25 years, who was operated upon in October, 1896. The pylorus looked and felt normal from the outside but would only admit the tip of a Spencer Wells artery forceps. He has remained well since operation; his general health is better than before and be can take ordinary food. In August last he weighed 9 stones 7 pounds, a gain of 2 stones 7 pounds since operation.

CASE 6.-A man, aged 42 years, was operated upon in March, 1897. There was no organic change at the pylorus and it was then suggested that the symptoms might be due to spasm. The patient has remained fairly well since opera. tion; he takes ordinary food in small quantities and has no vomiting but he complains that he does not gain strength. In August, 1904, he weighed 11 stones 10 pounds, a gain of 1 stone 5 pounds. He does his ordinary work.

CASE 7.-A man, aged 38 years, was operated upon in March, 1897. An ulcer was found on the posterior wall of the pylorus but there is no note as to stricture. This patient remained very well until the early part of 1901, when he had a "stomach attack," which lasted for two weeks ; in spite of this in June, 1901, he weighed 10 stones-a gain of 1 stone 7 pounds. Since then he has had a recurrence of his trouble each spring; he had pain after food and vomiting, but between the attacks was fairly well. For about three months before his re-admission to the hospital in June, 1904, he was quite ill with pain and vomiting and had lost flesh. The stomach was very much dilated and the vomit contained sarcinæ. On exploration the stomach was found to be dilated and there was an oedematous mass at the pylorus but there was no certain evidence as to its nature. Posterior gastro-enterostomy was performed; he made a good recovery and there followed a very rapid gain in weight.

CASE 8.-A woman, aged 39 years, was operated upon in September, 1897. The pylorus would not admit the tip of the forefinger. The patient has remained very well since the operation, her health is better than before, and she takes ordinary food. Since she reported herself in June, 1902, she has vomited once or twice every three months but there are no other symptoms and her gain in weight is now greater than it was at that time. In August, 1904, she weighed 8 stones 3 pounds, a gain of 2 stones 1 pound since the operation.

CASE 9.-A man, aged 56 years, was operated upon in September, 1897. The omentum was adherent to the pylorus which was hard to the touch and only admitted the tip of a 